\title{
APROVEITAMENTO DE ÁGUAS PLUVIAIS NO COMBATE A INCÊNDIOS, COMO FERRAMENTA DE GESTÃO AMBIENTAL NO 3 O GRUPAMENTO DE BOMBEIROS DE PERNAMBUCO
}

\begin{abstract}
Rogério Alves Siqueira ${ }^{1}$
RESUMO: A busca por maneiras de combater o desperdício e preservar os recursos hídricos, são questões fundamentais nos atuais sistemas de gestão ambiental em diversos setores, no sentido de reduzir os impactos causados ao meio ambiente. Este trabalho tem o objetivo de propor um modelo de gestão para aproveitamento de águas pluviais do $3^{\circ}$ Grupamento de Bombeiros no combate a incêndios. Através de tecnologias simplificadas, tais como, construção de reservatório, adequações hidráulicas, instalações de calha e condutores nos telhados, propoem-se reduzir a demanda de água sobre mananciais, visando o combate ao desperdício e o desenvolvimento sustentável através de práticas ambientalmente adequadas.
\end{abstract}

Palavras-chave: Recursos hídricos. Gestão ambiental. Incêndio.

ABSTRACT: The search for ways to combat waste and preserve water resources are fundamental issues in current environmental management systems in various sectors, in order to reduce the impacts caused to the environment. This work aims to propose a management model for the use of rainwater from the 3rd Fire Brigade in firefighting. Through simplified technologies, such as reservoir construction, hydraulic adjustments, gutter installations and roof conductors, it is proposed to reduce the demand for water on springs, aiming to combat waste and sustainable development through environmentally appropriate practices.

Keywords: Water resources. Environmental management. Fire.

\section{INTRODUÇÃO}

O Brasil é detentor de uma das maiores bacias hidrográficas do mundo, porém a escassez hídrica é uma realidade em várias regiões do país. Apesar da água de ser um recurso renovável, sua oferta não atende à demanda que com o passar do tempo vem aumentando substantivamente. Com isso sempre existirá um déficit, que cada vez está mais acentuado

\footnotetext{
I Bacharelando em Engenharia Civil pelo Instituto Federal de Pernambuco - IFPE, Campus Afogados da Ingazeira -PE; Curso de Formação de Oficiais Bombeiro Militar pela Academia Integrada de Defesa Social Campus de Ensino Mata (2010); Licenciatura em Ciências com Habilitação em Matemática pela Faculdade de Formação de Professores de Afogados da Ingazeira - FAFOPAI (2006); Curso de 2a Licenciatura em Química pelo Centro Universitário FIEO - UNIFIEO (2019); Curso de 2ª Licenciatura em Educação Física pela Faculdade Integrada de Brasília - FABRAS (2020); Pós-Graduação em Matemática pela Faculdade Integrada de Patos (2013); Pós-Graduação em Gestão de Emergência e Desastres, pela AVM Faculdades Integradas (2015); Pós-Graduação em Defesa Civil pela Faculdade UNYLEYA (2019) e Curso de Aperfeiçoamento de Oficiais Bombeiro Militar pela Academia Integrada de Defesa Social - Campus de ensino Mata (2018). E-mail: ras27@discente.ifpe.edu.br.
} 
pelo uso irracional e desperdícios diversos. O gerenciamento do uso da água e a busca por novas opções de abastecimento fazem parte do processo de desenvolvimento sustentável, que tem o propósito básico de prover adequadamente a água para o homem e ao meio ambiente.

A gestão dos recursos hidricos é normatizada, principalmente pela lei 6.938/8I, que institui a política nacional do meio ambiente e menciona o incentivo ao estudo e pesquisa de tecnologias orientadas para o uso racional e a proteção dos recursos ambientais; e a lei 9.433/97, que institui a política nacional de recursos hídricos, fixa os fundamentos, os objetivos, as diretrizes e os instrumentos capazes de indicar a orientação pública no processo de gerenciamento dos recursos hídricos, além de estabelecer entre os princípios de ações governamentais o incentivo ao estudo e pesquisa de tecnologias orientadas para o uso racional e a proteção dos recursos ambientais, bem como a racionalização do uso da água, instituindo a cobrança pelo uso da mesma, através de outorga.

O aproveitamento de águas pluviais funciona como uma importante ferramenta de gestão ambiental, levando-se em conta os critérios estabelecidos como padrões de qualidade, quando considerada as seguintes questões: a saúde pública, a preservação ambiental, a qualidade da fonte da água, a adequação para o uso pretendido e a aceitação do usuário.

Na região Nordeste, em especial no Sertão Pernambucano, a escassez de água, em determinados períodos do ano, é sempre recorrente. As condições climáticas associadas à falta de planejamento público são as maiores causas, principalmente pela falta de obras estruturantes adequadas a demanda, tais como barragens e adutoras.

Atualmente a Sede do 3음 Grupamento de Bombeiros (3 GB) do Corpo de Bombeiros Militar de Pernambuco (CBMPE), utiliza água do sistema de abastecimento, através de rede de hidrantes alocados em pontos disponinilizados pelo Companhia Pernambucana de Saneamento (COMPESA), na cidade de Serra Talhada, para utilização nas ocorrências de combate a incêndio.

Segundo dados da Agência Clima Tempo (2021), no segundo semestre as precicipitações reduzem drasticamente nessa região. E Segundo dados do CBMPE (Pernambuco, 2021, p.12), nesse mesmo período as ocorrências de combate a incêndio aumentam.

É de conhecimento geral que o aproveitamento de águas pluviais é sempre uma proposta de alternativas, entretanto, é fundamental que as premissas de seu novo uso tem que estar atrelado aos princípios da precaução, considerando a possibilidade sempre presente das contaminações sejam de metais pesados, produtos orgânicos altamente tóxicos ou de microrganismos.

Considerando os diversos benefícios advindos da implantação de programas de gestão ambiental, o principal objetivo desta pesquisa é analisar a viabilidade de sistema de aproveitamento de águas pluviais, verificando o potencial de redução do consumo de água potável e as economias geradas nas despesas de exploração de recursos hídricos.

\section{REFERENCIAL TEÓRICO}

\subsection{Aproveitamento de Águas Pluviais}

As técnicas de aproveitamento da água proveniente da chuva, a fim de ser reutilizada para fins domésticos, industrial e agrícola ganharam espaço em diversos países. Especialistas consideram esta dinâmica como sendo um meio simples e eficaz de reduzir os impactos ambientais relacionados com a progressiva escassez de água adequada para o 
consumo humano.

O sistema de aproveitamento de águas pluviais, consiste em captar a água da chuva captado pela cobertura da edificação, recolhida pelas calhas e conduzida por tubulação até um reservatório, passando por mecanismo de filtragem para remoção de impurezas e detritos, antes do armazenamento. O reservatório pode ser enterrado (cisterna) ou elevado, onde as tubulações específicas de água pluvial distribuem a água considerada apta ao consumo não potável (CARLON, 2005,p.i4).

Para instalação do sistema de aproveitamento de água pluvial, foram aplicadas a Norma Brasileira de Referência - NBR 5626 (ABNT, 1998), que se refere à instalação predial de água fria; a Norma Brasileira de Referência - NBR ro844 (ABNT,1989), que versa sobre instalações prediais de água pluviais e a Norma Brasileira de Referência - NBR 15527 (ABNT,2019), que versa sobre a Água de chuva - Aproveitamento de coberturas em áreas urbanas para fins não potáveis. As duas normas ditam os requisitos para o aproveitamento de água proveniente da chuva no perímetro urbano, para fins não potáveis, como também as normas para a concepção do projeto de coleta de água de chuva.

\section{2 Índice Pluviométrico}

O perfil histórico de precipitação do Sertão de Pernambuco apresenta grande variação de precipitações entre anos muito secos e muito chuvosos.

Seguem dados da climatologia da cidade de Serra Talhada (refere-se a média de 30 anos, compreendendo o período de $198 \mathrm{I}$ a 200I, em atendimento a recomendação da Organização Mundial de Meteorologia (OMM) (WMO, 1989) que prevê confiabilidade em conjunto de dados meteorológicos com registros de 30 anos ou mais) da Agencia Clima Tempo (202I), conforme Tabela I:

Tabela r. Climatologia e histórico de previsão do tempo em Serra Talhada

\begin{tabular}{cccc}
\hline Mês & Mínima $\left({ }^{\circ} \mathrm{C}\right)$ & Máxima $\left({ }^{\circ} \mathrm{C}\right)$ & Precipitação $(\mathrm{mm})$ \\
\hline Janeiro & $23^{\circ}$ & $33^{\circ}$ & 74 \\
Fevereiro & $22^{\circ}$ & $33^{\circ}$ & 107 \\
Março & $22^{\circ}$ & $32^{\circ}$ & 142 \\
Abril & $22^{\circ}$ & $31^{\circ}$ & I06 \\
Maio & $21^{\circ}$ & $30^{\circ}$ & 40 \\
Junho & $20^{\circ}$ & $29^{\circ}$ & 17 \\
Julho & $19^{\circ}$ & $29^{\circ}$ & II \\
Agosto & $19^{\circ}$ & $30^{\circ}$ & 6 \\
Setembro & $20^{\circ}$ & $33^{\circ}$ & 2 \\
Outubro & $21^{\circ}$ & $34^{\circ}$ & 4 \\
Novembro & $22^{\circ}$ & $35^{\circ}$ & 8 \\
Dezembro & $23^{\circ}$ & $34^{\circ}$ & 38 \\
\hline
\end{tabular}

Fonte: Agência Clima Tempo, 202I

\subsection{Sistema de Aproveitamento de Águas Pluviais}

O sistema de aproveitamento de água da chuva é estabelecido conforme a capacidade de captação da cobertura, conforme suas características estruturais, visto que não existe uma padronização nos aspectos construtivos das edificações. Deve-se levar em conta 
a área de contribuição (coberta) para dimensionamento do conjunto de calhas, condutores e do reservatório de armazenamento.

Considerando as recomendações da NBR io.844 (ABNT, I989, p.15), que regulamenta a Instalação Predial de Águas Pluviais, as vazões do projeto foram determinadas por meio da equação $\mathrm{I}$ :

Onde:

Equação I - Equação para cálculo de vazão pluvial.

$$
\mathbf{Q}=\mathbf{I} \cdot \frac{\mathbf{A}}{\mathbf{6 0}}
$$

$\mathrm{Q}=$ Vazão máxima $(1 / \mathrm{min})$;

$\mathrm{i}=$ Índice de precipitação pluviométrica $(\mathrm{mm} / \mathrm{h}) ; \mathrm{e}$

$\mathrm{A}=$ Área de contribuição $\left(\mathrm{m}^{2}\right)$.

Ainda de acordo com a NBR 10.844 (ABNT, 1989, p.15), para a determinação do índice de precipitação pluviométrica "i”, requer a fixação de valores corretos, a fim de que dure a precipitação e o período de retorno. Esse período que também é chamado de período de recorrência, é o intervalo de tempo (anos) de ocorrência de um determinado evento, e que para a obra do tipo coberturas e terraços, a duração da precipitação deve ser fixada, no mínimo, em 5 anos.

Para efeito de cálculo das áreas de contribuição, foi utilizada a equação para superfície inclinada, descrita na NBR ı.844 (ABNT, 1989, p.16), conforme Figura I.

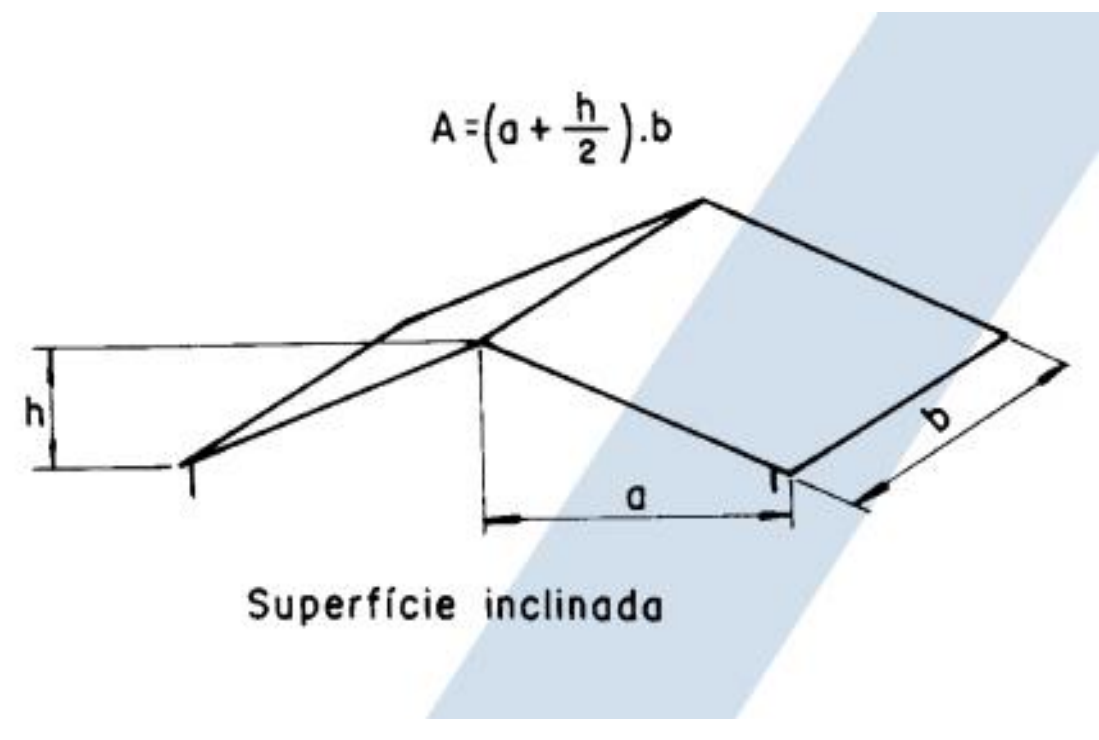

Figura I. Fórmulas para cálclo das áreas de contribuição.

Fonte: ABNT (1989).

A edificação da Sede do $3^{\circ}$ GB possui planta de coberta, conforme decrição das Figuras 2 e 3, possuindo inclinação de $38 \%$ no telhado. 
Figura 2. Planta da Coberta da Edificação.

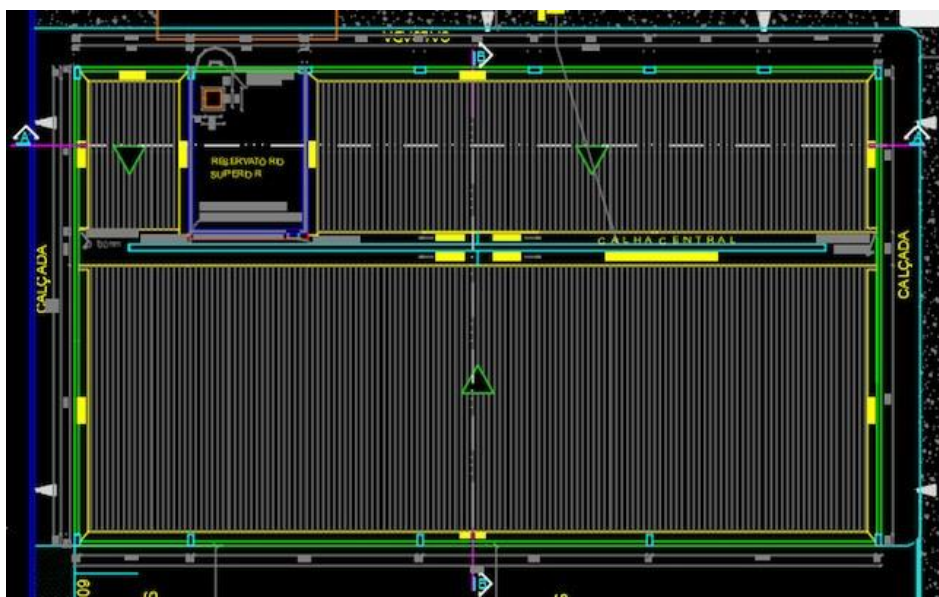

Fonte: O próprio autor (2021).

Figura 3. Cotas da cobertura da Sede do 3 o GB.

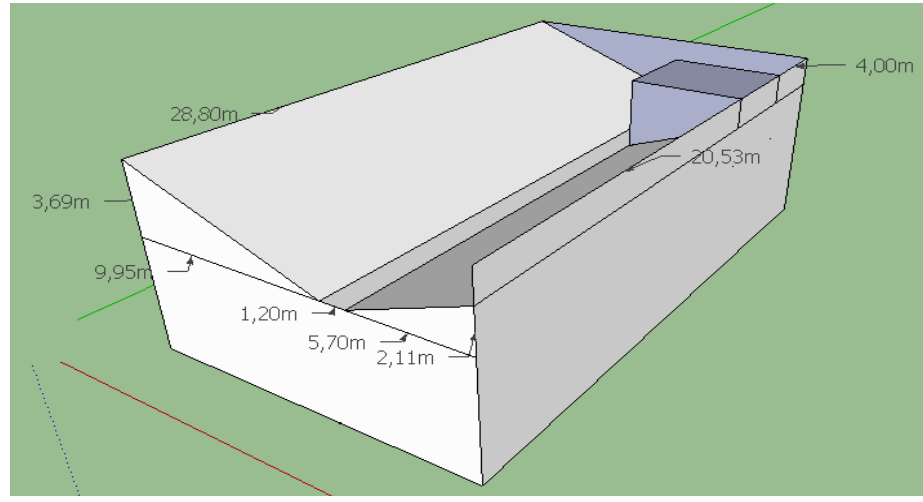

Fonte: $\mathrm{O}$ próprio autor, 2021

\subsection{Dimensionamento das Calhas}

As Cartas Pluviométricas indicam a quantidade de água que cai e que é indicada em "milímetros" ( $\mathrm{mm})$. São geralmente a quantidade total de água que cai durante o ano. Porém para o cálculo da quantidade de água, o que se leva em consideração é apenas a maior intensidade (força) da chuva.

Mesmo em regiões de poucas chuvas como no sertão pernambucano, quando chove a chuva pode ter uma intensidade pluviométrica tão grande como uma chuva em lugares muito chuvosos. Não é a quantidade total de água que cai, mas sim a quantidade em um determinado tempo. O que importa para dimensionamento das calhas e condutores é a intensidade pluviométrica, isto é, os milímetros por hora, por metro quadrado $\left(\mathrm{mm} / \mathrm{h} . \mathrm{m}^{2}\right)$ ou os litros por minuto, por metro quadrado $\left(\mathrm{L} / \mathrm{min} \cdot \mathrm{m}^{2}\right)$.

Logo adotando o valor com maior índice pluviométrico da cidade de Serra Talhada, como estimativa de período de retorno, que é de $142 \mathrm{~mm} / \mathrm{h} \cdot \mathrm{m}^{2}$, ou $2,37 \mathrm{~L} / \mathrm{min} \cdot \mathrm{m}^{2}$ (AGÊNCIA CLIMA TEMPO, 2021, p.23), o sistema estará seguro quanto ao risco de transbordamento das calhas. 
Existem muitos modelos de calhas e a escolha se faz em função das características arquitetônicas do edifício e a capacidade de vazão delas é em função da forma da seção transversal, conforme Figura 4:

Figura 4. Tipos de Calhas

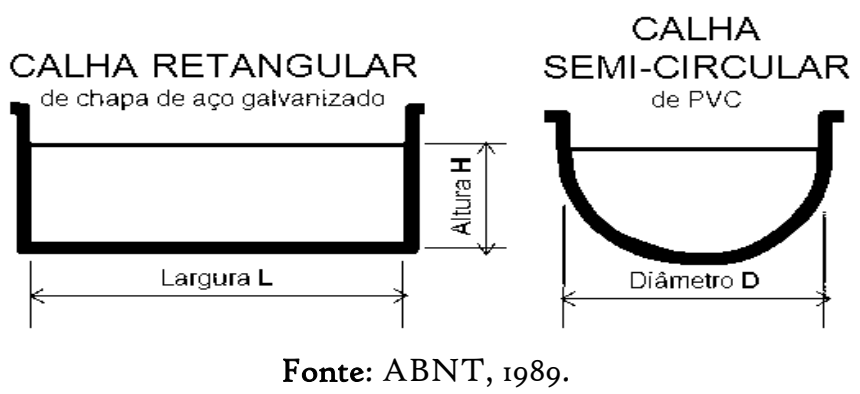

A calha deve ter dimensões que consigam dar vazão ao volume de água fornecida pela cobertura. A NBR 10844 (ABNT, 1989, p.19) dá as vazões para um caimento de $2 \%$, conforme Tabela 2.

Tabela 2. Dimensões de calhas.

\begin{tabular}{|c|c|c|c|c|}
\hline \multicolumn{3}{|c|}{$\begin{array}{l}\text { CALHA RETANGULAR } \\
\text { de chapa de aço galvanizado }\end{array}$} & \multicolumn{2}{|c|}{$\begin{array}{c}\text { CALHA SEMICIRCULAR } \\
\text { de PVC }\end{array}$} \\
\hline $\begin{array}{l}\text { LARGURA L } \\
\text { centímetros }\end{array}$ & $\begin{array}{l}\text { ALTURA H } \\
\text { centímetros }\end{array}$ & $\begin{array}{c}\text { VAZÃO Q } \\
\text { litros por minuto }\end{array}$ & $\begin{array}{l}\text { DIÂMETRO } \\
\text { milímetros }\end{array}$ & $\begin{array}{c}\text { VAZÃO Q } \\
\text { Litros por minuto }\end{array}$ \\
\hline I5 & 7 & 375 & I00 & 348 \\
\hline 20 & IO & 886 & 150 & 1.026 \\
\hline 30 & 15 & 2.612 & 200 & 2.209 \\
\hline 40 & 20 & 5.625 & 250 & 4.005 \\
\hline
\end{tabular}

Fonte: ABNT, 1989 .

Consultando a tabela acima, observa-se que a calha que atenderia a vazão de 1.67o litros por minuto seria a com largura $30 \mathrm{~cm}$ por $15 \mathrm{~cm}$ de altura (calha retangular), deixando uma margem de segurança acima do limite da vazão.

\subsubsection{Dimensionamento dos Condutores}

Segundo a NBR 10.844 (ABNT, 1989, p.19), os condutores verticais devem ser projetados, sempre que possível, em uma só prumada, evitando desvios, curvas, trechos inclinados e horizontais, porém quando houver necessidade de desvio, devem ser usadas curvas de $90^{\circ}$ de raio longo ou curvas de $45^{\circ}$ e devem ser previstas peças de inspeção.

Qualquer inclinação favorecerá a formação do vórtice que criará uma sucção do ar. Sem qualquer inclinação a saída da água da calha ocorre no regime de escoamento livre. 
Grelhas e outros objetos instalados na boca do Tubo de Queda agirão contra a formação do afogamento. Além disso, as folhas de árvores que caírem no telhado e carregadas pela enxurrada para as calhas entopem as grelhas e causam transbordamento.

O dimensionamento dos condutores verticais deve ser feito a partir dos seguintes dados: $\mathrm{Q}=\mathrm{Vazão}$ de projeto, em $\mathrm{L} / \mathrm{min} ; \mathrm{H}$ = altura da lâmina de água na calha, em $\mathrm{mm}$; e $\mathrm{L}=$ comprimento do condutor vertical, em $\mathrm{m}$. Não há uma fórmula de fácil manipulação $\mathrm{e}$ os parâmetros envolvidos são determinados de forma experimental ou por meio de ábaco (nomograma), conforme Figura 5.

Figura 5. Ábaco.

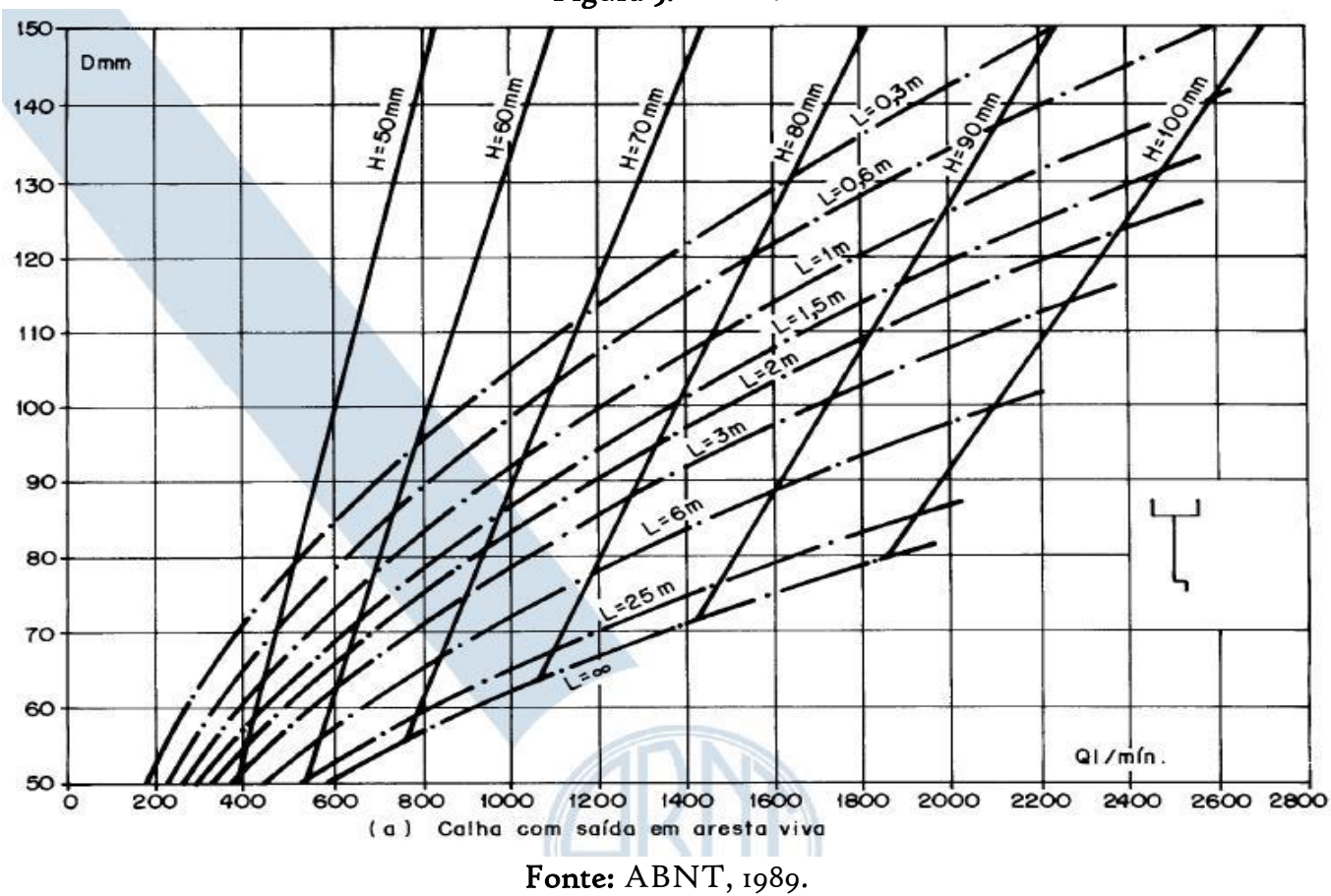

No $3^{\text {o }}$ GB foram colocados 8 condutores de descida nas posições indicadas nas Figuras 6,7 e 8 . A água da chuva que cai será recolhida pela Calha única e que desce pelos condutores.

Figura 6. Lateral esquerda da edificação (imagem meramente ilustrativa)

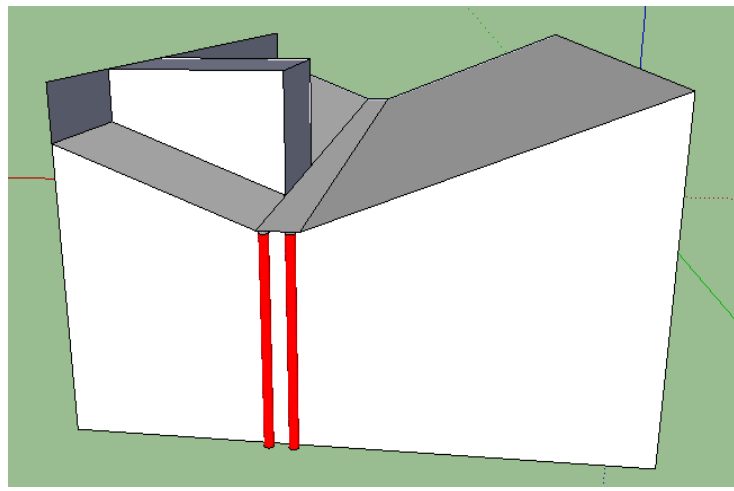

Fonte: O próprio autor, 2021. 
Figura 7. Lateral direita da edificação (imagem meramente ilustrativa)

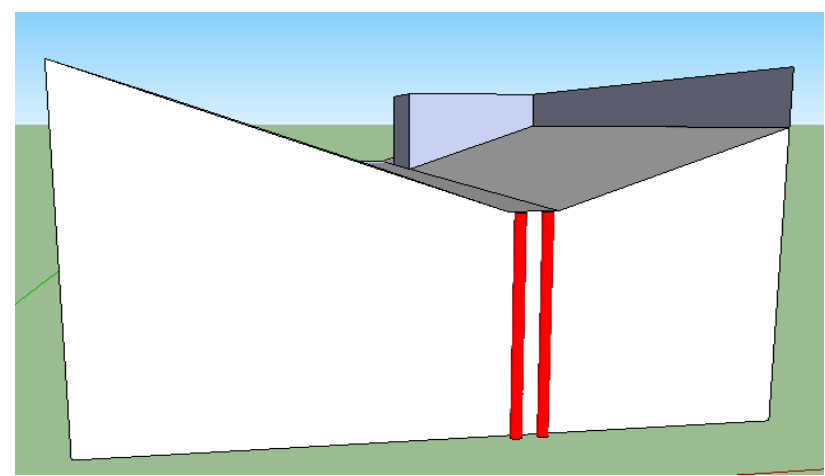

Fonte: $\mathrm{O}$ próprio autor, 202I.

Figura 8. Fundos da edificação (imagem meramente ilustrativa)

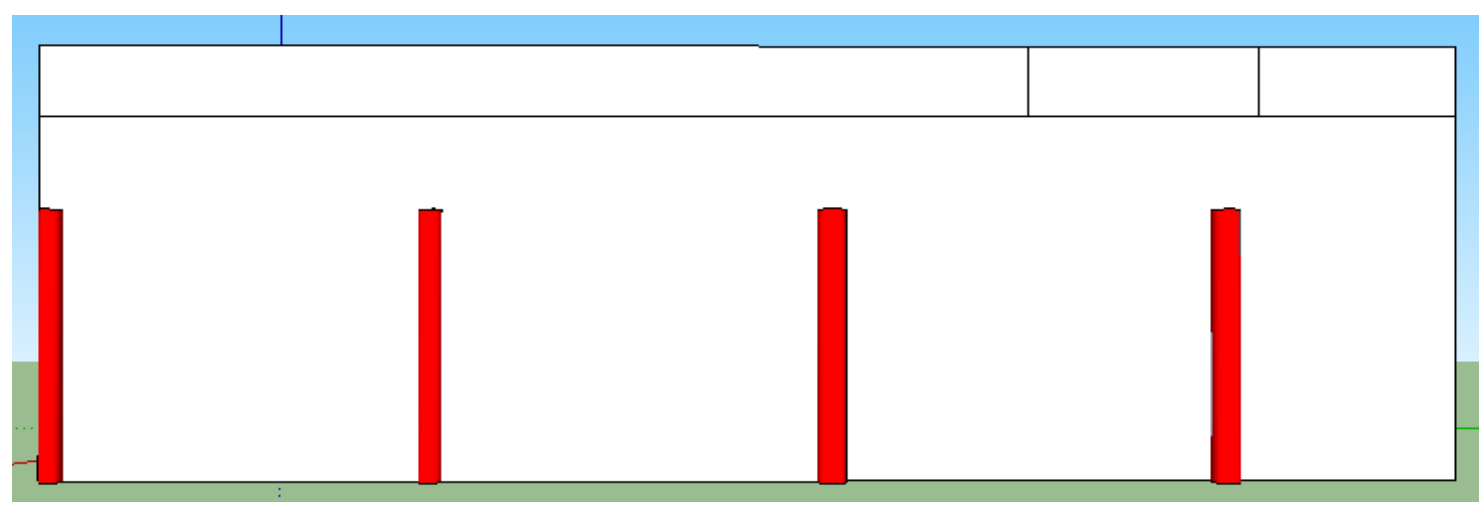

Fonte: $\mathrm{O}$ próprio autor, 202I.

Os pontos de descida de água devem ser livres de interferências, tais como janelas, portas, antenas, etc. Neste caso, algumas janelas estão interferindo na descida dos condutores, conforme Figura 9, porém estas podem ser inutilizadas, visto que os referidos cômodos possuem janelas em outros pontos da edificação.

Figura 9. Vista da lateral esquerda da Sede do $3^{\circ}$ GB

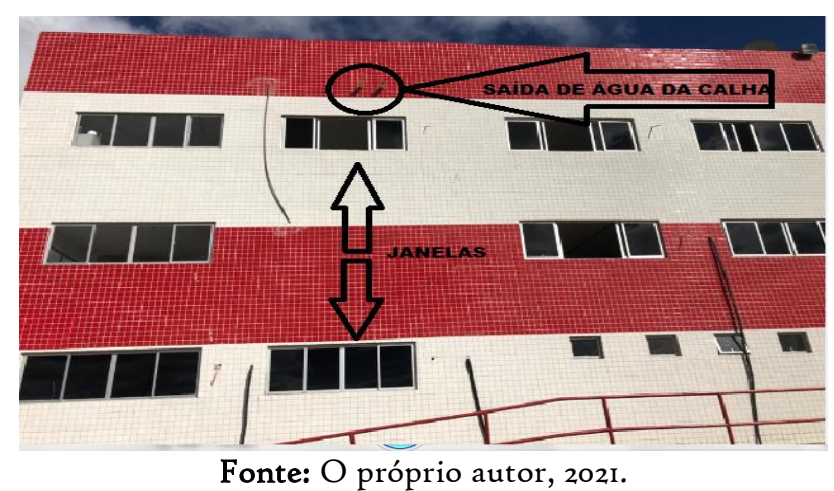

A vazão da calha é calculada pela fórmula na Figura I, conforme NBR ro.844/1989. 
Logo teremos um vazão total de I.195 litros por minuto, sendo distribuida por 8 (oito) condutores numa razão de 149,38 litros por minuto por condutor. Isso considerando que a calha está com nível de escoamento prumado.

\subsubsection{Dimensionamento do Reservatório}

O reservatório foi dimensionado utilizando os dados de Médias históricas do município de Serra Talhada da Agência Clima Tempo (202I). Os valores utilizados representam o comportamento da chuva e da temperatura ao longo do ano. As médias climatológicas são valores calculados a partir de um série de dados de 30 anos observados, conforme Tabela I.

O sistema de aproveitamento de águas pluviais pode seguir diferentes esquemas e que segundo Annecchini (2005), existem quatro modelos que se destacam, são eles: sistema de fluxo total, sistema com derivação, sistema com volume adicional de retenção e sistema com infiltração no solo.

Para dimensiomanto do sistema, foi adotado o modelo de fluxo total, que de acordo com Annecchini (2005, p.29), toda a chuva coletada pela superfície de captação é direcionada ao reservatório de armazenamento, passando antes por um processo de filtargem ou retenção de impurezas, conforme a Figuras io.

Figura 1o. Sistema de fluxo total

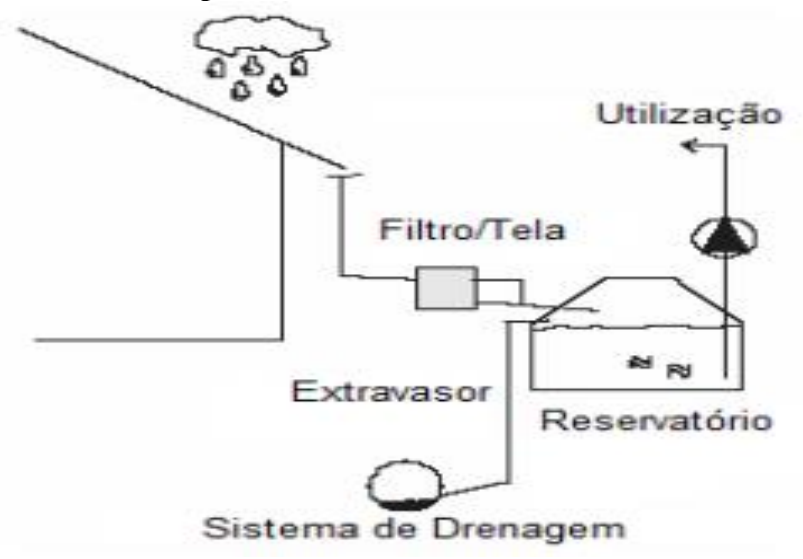

Fonte: Annecchini, 2005.

Este esquema permite que o escolamento total da água seja conduzido ao reservatório, passando antes por um filtro. O extravazamento apenas ocorre após o reservatório estiver completamente cheio.

O cálculo do volume de água de chuva depende de algumas variáveis, tais como precipitação, área de captação, coeficiente de escoamento da área de cobertura e Eficiencia do sistema de captação, podendo ser estimado pela Equação 2, conforme NBR 15527 (ABNT, 2019, p.22).

Onde:

Equação 2 - Equação para cálculo de vazão pluvial.

$$
\text { Vdisp }=\text { P.A.C.n }
$$

Vdisp = Volume disponível anual, mensal ou diário de água de chuva (litros);

$\mathrm{P}=$ Precipitação média anual, mensal ou diário de água de chuva (milímetros);

$\mathrm{A}=$ Área de coleta $\left(\mathrm{m}^{2}\right)$; 
$\mathrm{C}=$ Coeficiente de escoamento superficial da cubertura (runoff);

$\mathrm{n}=$ Eficiencia do sistema de captação (Recomenda-se utilizar o fator 0,85 ).

\subsection{Estrutura Tarifária de Consumo de Água}

Segundo Resolução da Agência Reguladora do Estado de Pernambuco (ARPE) no I70 (Pernambuco, 2020, p.29), a estrutura tarifária para consumo de água de órgão publicos segue, conforme Tabela 3.

Tabela 3. Tarifa para consumo de órgaos públicos

\begin{tabular}{cc}
\hline Consumo & Valor (R\$) \\
\hline Até 10.000 litros/mês & 64,17 \\
I0.001 a 999999.000 litros & 9,73 \\
\hline \multicolumn{2}{c}{ Fonte: Pernambuco, 2020. }
\end{tabular}

Considerando que para cada metro cúbico (mil litros) de água consumida, há um acrescimo à tarifa mínima de $\mathrm{R} \$ 9,73$ (nove reais e setenta e três centavos) na tarifa mínima, por exemplo, caso o consumo mensal seja igual a 30 metros cúbicos de água, teríamos o seguinte cálculo: $64,17+(20 \times 9,73)=258,77$.

\section{MATERIAIS E MÉTODOS}

Para a elaboração deste trabalho, foi realizada uma pesquisa bibliográfica sobre os aspectos relacionados à gestão ambiental da escassez de água. De posse das informações constantes da literatura, foi desenvolvido um sistema relacionado ao aproveitamento de águas pluviais, a qual abastecerá as viaturas de combate a incêndio. Este estudo relaciona-se com o uso não potável, proveniente da água de chuva.

O Sistema inclui uma calha na cobertura, condutores e um reservatório para captação de água pluvial. Esse projeto visa reduzir o uso de água potável em viaturas de combate a incêndio, substituindo-a por aguá coletada da chuva.

Para o dimensionamento de todos os componentes do sistema foram utilizadas as normas brasileiras: NBR 15527 (ABNT, 2019); NBR 5626 (ABNT, 1998) e a NBR 10844 (ABNT, 1989). Tudo isso tendo em vista a análise da viabilidade técnica, estratégica e econômico-financeira do projeto e quais benefícios irá trazer tanto para o CBMPE, quando para a sociedade.

Também foram analisados dados estatístico referentes à Climatologia e histórico de previsão do tempo em Serra Talhada, bem como aos dados de atendimento à ocorrencias de combate a incêndios, durantes os anos de 2019 e 2020, na área de atuação da I Bombeiros do $3^{\circ} \mathrm{GB}$.

\section{RESULTADOS E DISCUSSÃO}

Após detida análise nos dados apurados, foi possível dimensionar o reservatório para a sede do $3^{\circ}$ GB em Serra Talhada, de modo que permita um melhor aproveitamento do potencial máximo de captação do sistema.

Ao averiguar a planta de coberta da Sede do $3^{\circ} \mathrm{GB}$, que abriga as instalações da $I^{\underline{a}}$ Seção de Bombeiros, que é responsável, além de outras atribuições, pelo combate à incêndios 
em 6 municípios do interior do estado de Pernambuco (Betânia, Calumbi, Flores, Santa Cruz da Baixa Verde, Serra Talhada e Triunfo), utilzando os cálculos estabelecidos através da NBR ro.844 (ABNT, 1989), foi totalizada uma área de contribuição, equivalente a $505 \mathrm{~m}^{2}$ (metros quadrados).

Para o cálculo de vazão da calha e dos condutores, foi utilizado como referência o mês com maior índice pluviométrico na média histórica (março), equivalente a ${ }^{142}$ milímetro, visto que esses valores superam o valor estabelecido pelo período de retorno, conforme NBR ro.844 (ABNT,1989).

Aplicando a Equação para cálculo de vazão pluvial na calha, conforme NBR io.844 (ABNT,1989), chegamos a uma capacidade de vazão máxima de aproximadamente 1.195 litros por minuto.

Embora a calha recomendada para atender a vazão acima, seja a com largura de 30 $\mathrm{cm}$ por $15 \mathrm{~cm}$ de altura (calha retangular), constatou-se que já existe uma calha com dimensões superiores as da Tabela 2, possibilitando uma margem bem maior, o que permite uma tolerância maior às obstruções.

Consultando o ábaco da Figura 7, conforme NBR io.844 (ABNT, 1989), conclui-se que com a utilização da calha e saídas de água existentes, haverá o escoamento da água recolhida no telhado sem causar transbordamento na cobertura da edificação.

Aplicando-se o cálculo do volume disponível de água de chuva, através da equação 2, conforme NBR 15527 (ABNT, 2019), e considerando o pior cenário possível, ao desconsiderar o coeficiente de "runoff", a norma trata as superfícies de captação como totalmente impermeáveis, ou seja, $\mathrm{c}=\mathrm{I}$, encontramos um valor aproximado do volume do reservátorio, equivalente a $238,2 \mathrm{~m}^{3}$ (metros cúbicos).

O sistema estabelecido para instalação, seguiu o esquema de fluxo total, conforme figura II.Figura II. Fluxograma do sistema de aproveitamento de águas pluviais.

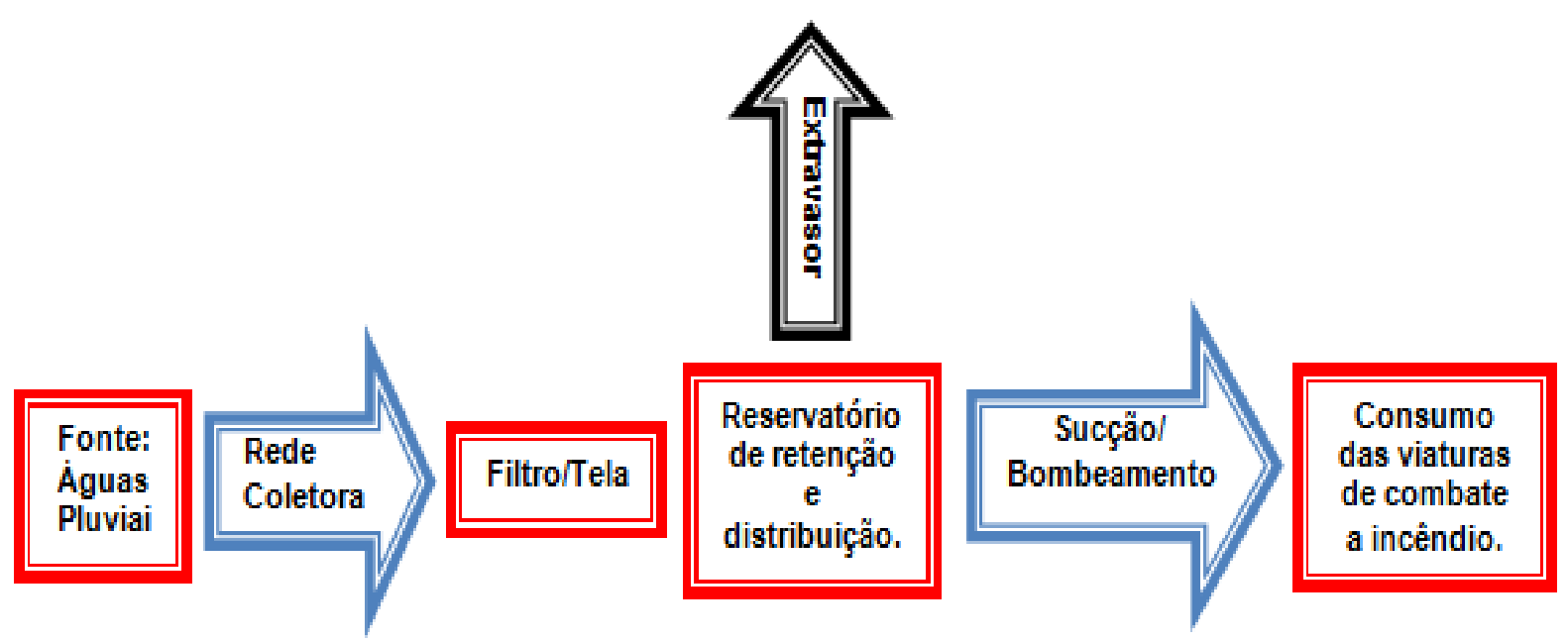

Fonte: $\mathrm{O}$ proprio autor, 202I.

Observando os dados estatísticos do CBMPE, da área de atuação da I ${ }^{\text {a }}$ Seção de Bombeiros do $3^{\mathrm{o}} \mathrm{GB}$, no período compreendido entre os anos de 2019 a 2020, relativos às ocorrências de combate a incêndio, foram atendidos os quantitativos de 252 e 249, respectivamente, de ocorrências de incêndio, conforme descrição do Gráfico I (PERNAMBUCO, 2021, p.30). 
Gráfico I - Número de ocorrências de combate a incêndio, atendidas pela Iํㅗ Seção de Bombeiros do $3^{\circ}$ GB, no período compreendido entre 2019 e 2020 .

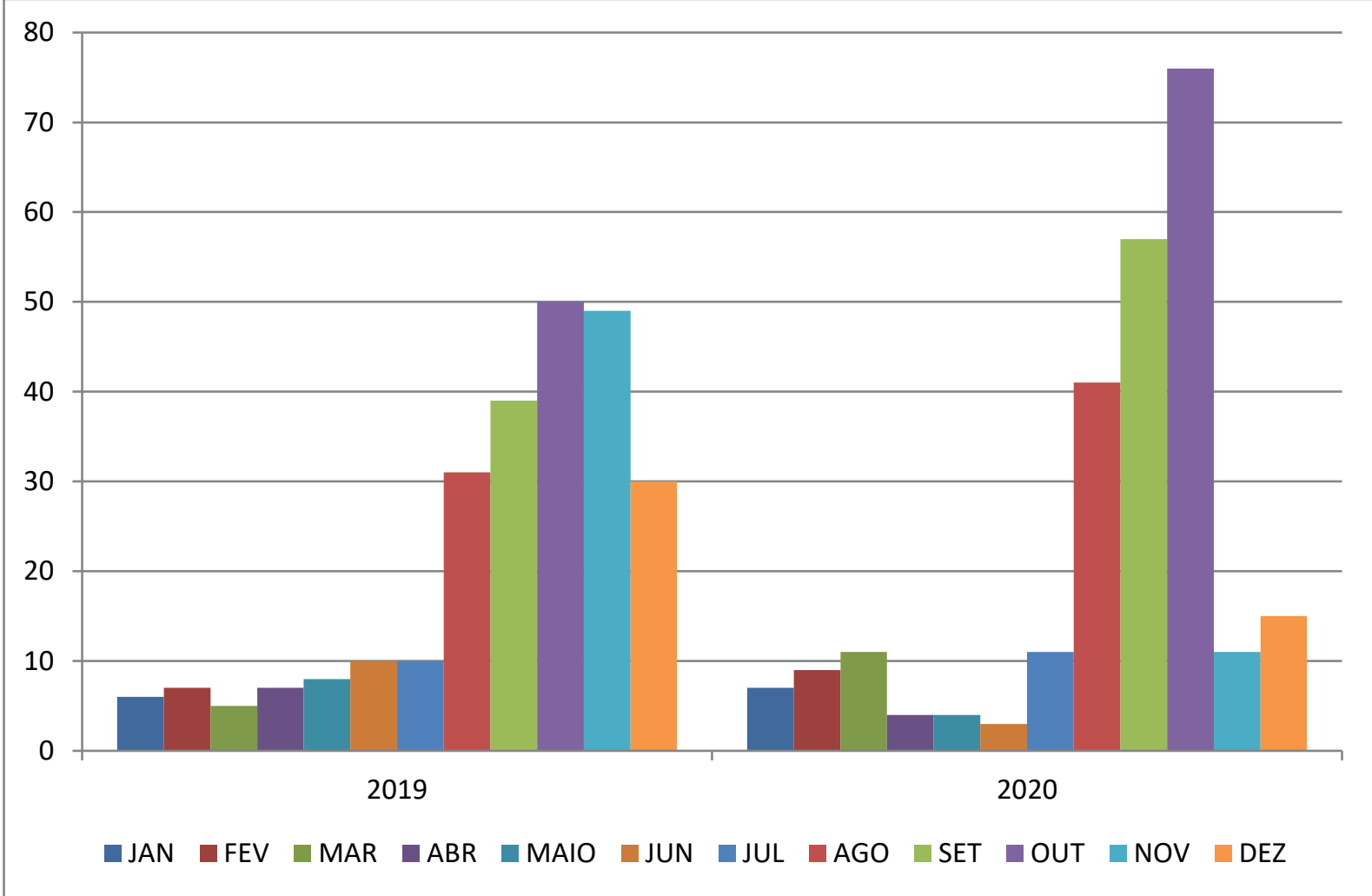

Fonte: Pernambuco (202I).

Nota-se que existe uma demanda com valores bastante significativos de ocorrências de combate a incêndios, atendidas pela referida unidade operacional, sendo que no segundo semestre dos anos em estudo, essas ocorrencias sofreram um aumento vertiginoso. Sem contar que no referido período a demanda por água aumenta, enquanto que há redução do volume de água dos reservatórios por falta de chuvas.

Atualmente as alternativas, caso a COMPESA esteja impossibilitada de fornecer água para o abastecimento das viaturas de combate a incêndios, são os reservatórios: Açude Cachoeira II, localizado no bairro Cachoeira; Açude Borborema, localizado no bairro Bom Jesus e o Açude Saco localizado bairro José Tomé de Souza Ramos, todos na cidade de Serra Talhada, porém estas opções não são ambientalmente viáveis, visto que o uso de água de manancial não contribui para o desenvolvimento sustentável.

A redução das chuvas, as altas temperaturas, a baixa umidade e o aumento de materiais de fácil combustão, tais como folhas secas e vegetação morta, na região neste período, contribuem para o aumento de focos de incêndio em vegetação.

Outro fator que historicamento contribui para o aumento de queimadas são as práticas agrícolas da região, onde os agricultores utilizam técnicas antigas e amplamente usada no Brasil. Segundo Miranda, Moraes e Oshiro (2006) as queimadas são utilizadas por produtores rurais, como técnicas primitivas para limpeza dos solos após o desmatamento da vegetação e queima de pragas das plantações.

O Gráfico 2 (PERNAMBUCO, 202I) descreve a evolução do numero de incêndio em vegetação durante os anos de 2019 e 2020. 
Gráfico 2 - Número de ocorrências de combate a incêndio em vegetação, atendidas pela I ${ }^{\text {a }}$ Seção de Bombeiros do $3^{\circ} \mathrm{GB}$, no período compreendido entre 2019 e 2020 .

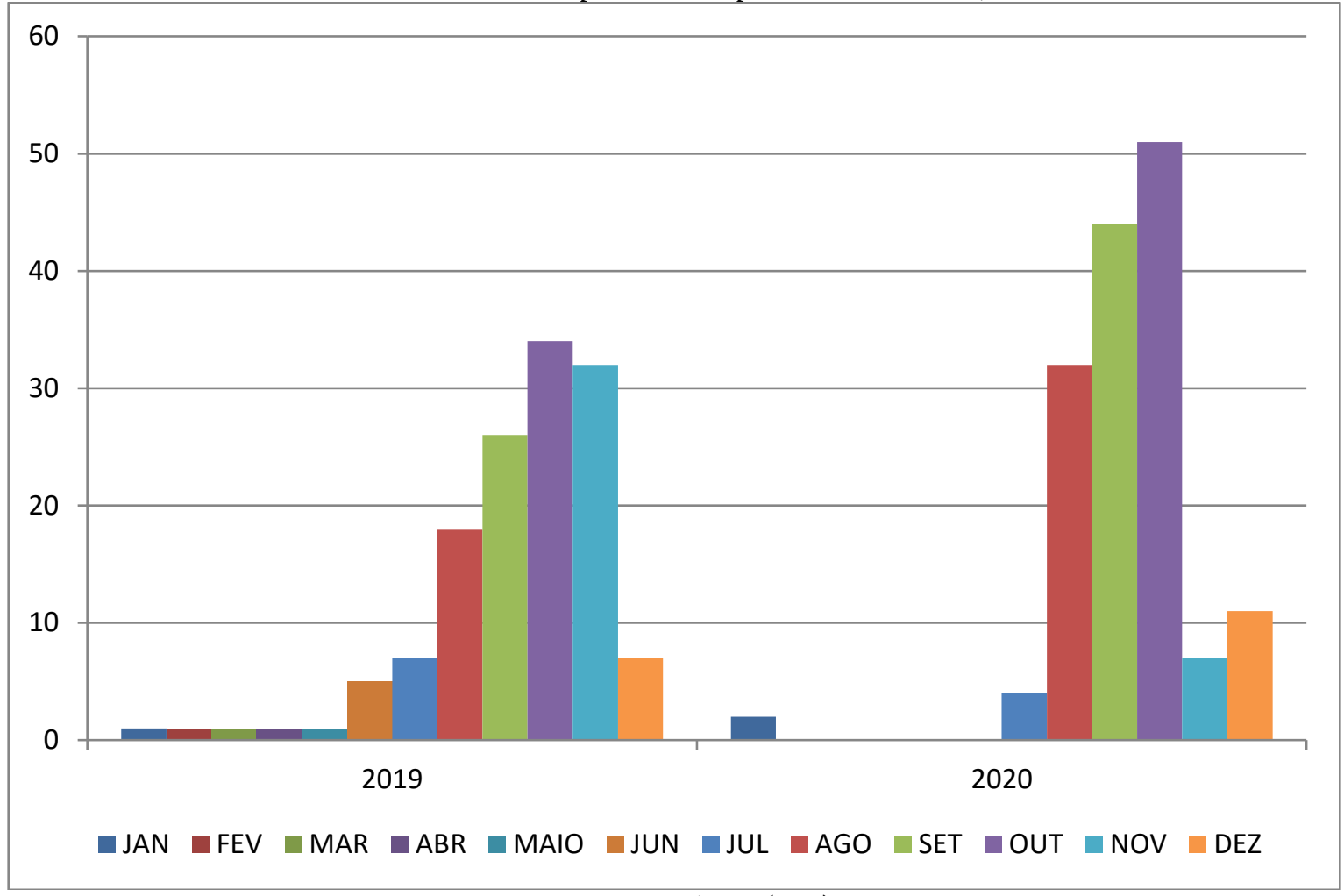

Fonte: Pernambuco (2021).

Nota-se que o grupo de ocorrência, o incêndio em vegetação, representa um total de $53,17 \%$ de todas as ocorrências de incêndio atendidas em 2019 e de $60,64 \%$ de todas as ocorrências de incêndio atendidas em 2020 (PERNAMBUCO, 202I).

Os sistemas de combate a incêndio a cada dia se aperfeiçoam, possibilitando assim, que os Corpos de Bombeiros também façam gestão no uso da água, seja aplicando táticas e técnicas que permitam a redução da quantidade de água utilizada, e/ou da forma como propõem este trabalho, através do aproveitamento de águas pluviais.

Do ponto de vista econômico, há uma perspectica, com o advento desse sistema de aproveitamento da água captada, que seria utilizado para o cambate a incêndio na área de atuação da I ${ }^{\underline{a}}$ Seção de Bombeiros do $3^{\circ}$ GB, tem-se, de acordo com a análise realizada, uma economia em torno de até 238,2 mil litros de água por ano, ou 19,85 mil litros mensais.

Do ponto de vista ambiental, com a implantação do sistema de aproveitamento de águas pluviais a demanda por água do sistema de abastecimento da COMPESA irá diminuir drasticamente, reduzindo de sobremaneira o desperdício de água e consequentimente os impactos causados ao meio ambiente.

\section{CONSIDERAÇÕES FINAIS}

A água é um dos recursos mais valiosos e de maior uso no mundo. $O$ combate a sua escassez é um dos grandes desafios que a sociedade atual terá que enfrentar para a preservação das gerações futuras. Apesar de termos ainda grandes mananciais de água doce 
disponíveis, a utilização deste insumo cresce a cada dia.

Com a utilização de novas tecnologias, pode-se acelerar o desenvolvimento de diversos modelos de uso racional da água. A possibilidade de aproveitamento das águas de chuva certamente resultará na diminuição do consumo de água tratada que é fornecida pela companhia de saneamento.

O estudo evidenciou que o aproveitamento das águas pluviais é uma alternativa importante no combate à escassez da água, principalmente, numa região em que as médias pluviométricas são bastante reduzidas e mal distribuídas. E que tal sistema deve ser aplicado como ferramenta de gestão ambiental, como uma opção tecnológica simples, pois reduz o uso de água proveniente de mananciais naturais protegidos por leis.

Assim como qualquer modelo de captação de água pluvial utilizado no mundo, este modelo apresentado também requer um custo inicial de instalação, que pode ser considerado como significativo, porém a longo prazo deve-se ter economia no volume de água da COMPESA, utilizada pelas viaturas de combate a incêndio. Consequentemente isso trará impactos socioambientais na localidade, pois ao aproveitar a água que antes voltava para a natureza, haverá a preservação da qualidade desse bem que é muito importante para o bemestar e para a qualidade de vida das pessoas.

\section{REFERÊNCIAS}

ABNT. Associação Brasileira De Normas Técnicas. NBR 15527: Água de chuva Aproveitamento de coberturas em áreas urbanas para fins não potáveis - Requisitos. $2^{\underline{a}}$ edição. Rio de Janeiro, abr. 2019.

. Associação Brasileira De Normas Técnicas. NBR 5626: Instalação predial de água fria. Rio de Janeiro, set. 1998.

. Associação Brasileira De Normas Técnicas. NBR ro844: Instalações Prediais de Águas Pluviais. Rio de Janeiro, dez. 1989.

Agência Clima Tempo. Climatologia e histórico de previsão do tempo em Serra Talhada, BR. Disponível em:

〈https://www.climatempo.com.br/climatologia/r270/serratalhada-pe. Acesso em i3 jun. 2021.

ANNECCHINI, K. P. V. 2005. Aproveitamento de água da chuva para fins não potáveis na cidade de Vitória (ES). Dissertação (Mestrado em Engenharia Ambiental). Vitória: Universidade Federal do Espírito Santo : s.n., 2005.

BRASIL. Lei no 6.938, de 31 de agosto de 1981. Dispõe sobre a Política Nacional do Meio Ambiente, seus fins e mecanismos de formulação e aplicação, e dá outras providências.

Disponível em: 〈http://www.planalto.gov.br/Ccivil_03/Leis/L6938.htm〉. Acesso em I2 jun. 2021.

Lei no 9.433, de 8 de janeiro de 1997. Institui a Política Nacional de Recursos Hídricos, cria o Sistema Nacional de Gerenciamento de Recursos Hídricos, regulamenta o inciso XIX 
do art. 2i da Constituição Federal, e altera o art. Io da Lei no 8.oor, de 13 de março de I990, que modificou a Lei $\mathrm{n}^{\mathrm{o}}$ 7.990, de 28 de dezembro de 1989.. Disponível em: 〈https://www.planalto.gov.br/ccivil_03/LEIS/L9433.htm> Acesso em: 28 jun. 2021.

CARLON, M. R. Percepção dos atores sociais quanto às alternativas de implantação de sistemas de captação e aproveitamento de água de chuva em Joinville - SC. 2005. 5of. Dissertação (Mestrado em Ciência e Tecnologia do Meio Ambiente) - Universidade do Vale do Itajaí, Joinville, 2005. Disponível em:

<https://www.bdc.ib.unicamp.br/bdc/visualizarMaterial.php?idMaterial=758\&alterarIdio $\mathrm{ma}=\operatorname{sim} \&$ novoldioma $=\mathrm{pt} \#$. YO 4 e6BtKjMw $>$. Acesso em 13 jun. 202I.

MIRANDA, E. E. de; MORAES, A. V. C. de; OSHIRO, O.T. Queimada na Amazônia Brasileira em 2005. Comunicado Técnico I8. EMBRAPA: São Paulo, 2006. Disponível em: 〈https://www.cnpm.embrapa.br/publica/download/coti9_bal_ucstiso6_vf.pdf $\rangle$. Acesso em: 20/06/2021.

PERNAMBUCO. Corpo de Bombeiros Militar, Estatística das ocorrências de orjanzorg até 3Idez2020 das OBM's - DINTER2, 202I.

.Resolução da Agência Reguladora de Pernambuco no 170/2020 - Publicada no DOE no 227 de 04/12/2020.

WMO. Calculation of monthly and annual 30-yearstandard normals, WCDP No. io, WMOTD No. 34I. World Meteorological Organization, Geneva. 1989. 